duty cf studying and directing all measures necessary for the control of injurious, and the conservation of desirable, species. Except that the Federation is specially concerned to urge the adoption of humane methods in the destruction of animal pests, its aims seem to differ little from those of several other existing organizations, such as those concerned with national parks, nature reserves, and the like. Further discussion will doubtless emphasize the importance of co-operation rather than competition in this, as in so many other schemes for post-war progress.

\section{Inter-allied Bureau for Educational Reconstruction}

Aw the sixth meeting of the Conference of Ministers of Education of the Allied Governments held at the offices of the Board of Education on October 5 , it was agreed to establish an Inter-Allied Bureau to carry out the practical steps needed to restore educational services in the countries concerned. This Bureau will be the executive body of the Conference. The work to be undertaken by the Bureau includes the purchase and distribution of books and periodicals, the preparation of films and other visual aids and the supply of scientific equipment. These matters are at present being considered by commissions of the Conference. The Bureau was also asked to consider financial needs and methods of contribution by Governments and the establishment of an inter-Allied secretariat.

\section{Recent Earthquakes}

The United States Coast and Geodetic Survey, in co-operation with Science Service and the Jesuit Seismological Association, has determined the epicentres of four recent earthquakes. These are in scattered localities but are all in areas where earthquakes are known to be relatively frequent. The first was on July 23,1943 , at $15 \mathrm{~h}$. $52.9 \mathrm{~m}$. U.T. and occurred near lat. $10 \cdot 5^{\circ} \mathrm{S}$, long. $117 \cdot 5^{\circ} \mathrm{E}$. This is in the Indian Ocean south of the island of Soembawa, approximately between Java and Australia. The next two came from the same epicentre, the second thus being an aftershock of the first, and together showing the tendency of earthquakes to recur from the same epicentre. The first of these was on July 29, at $3 \mathrm{~h} .02 \mathrm{~m} .14 \mathrm{~s}$. U.T., from an epicentre noar lat. $18 \cdot 9^{\circ} \mathrm{N}$., long. $67^{\circ} \mathrm{W}$., which is in the Atlantic Ocean between Nares Deep and tho island of Puerto Rico and north of the latter. The aftershock occurred on the next day, July 30 , at $1 \mathrm{~h} .02 \mathrm{~m}$. $32 \mathrm{~s}$. U.T. from the same epicentre in the West Indies. The fourth earthquake oceurrod on August 10 at 15h. $13.3 \mathrm{~m}$. U.T. from an epicentre near lat. $54^{\circ} \mathrm{N}$,, long. $161^{\circ} \mathrm{F}$., which is approximately in the middle of the east coast of the Kamchatka Peninsula and midway ketween the towns of Ust-Kamchatsk and Petropavlovsk-Kamchatski. The east coast of the Kamchatka Peninsula forms part of the circum-Pacific chain of instability, lying between the Japanese Islands and the Aleutian Islands. The depths of focus of all four earthquakes are considered normal and the interpretations and calculations are tentative. Data were received from seismological observatories in North and South America, Honolulu, New Zealand and Australia.

\section{Comet Oterma (1943a)}

As orbit for Comet Oterma, 1943a, has been computed, and its eccentricity is only a little more than half that of Pluto. As a result of this small eccentricity, it will be possible to observe the comet easily throughout its orbit. This is the second comet so far discovered which possesses this distinction, the other comet being Schwassmann-Wachmann (1925, ii). The eccentricities are 0.139 for Comet $1943 \alpha$ and 0.142 for Comet 1925, ii ; but the periods are very different, namely, 8 years and $16 \cdot 3$ years respectively.

The elements of the orbit of Comet Oterma are given kelow, but as it is at a considerable distance from the sun and the earth, it is not an easy object except for moderate-sized telescopes.

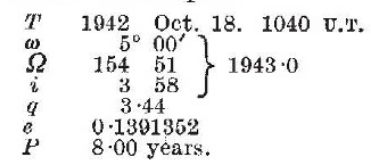

\section{Nova Aquilæe}

A TELEGRAM from Copenhagen announces that this nova attained magnitude 7 at the outburst between April 13 and May 2. Its position, referred to the equinox of 1855 , is R.A. $19 \mathrm{~h} .45 \cdot 5 \mathrm{~m}$., Dec. $8^{\circ} 06^{\prime} \mathrm{N}$. It is a little brighter than magnitude 12 at present.

\section{Announcements}

MR. J. BENSTEAD, general secretary of the National Union of Railwaymen, and Mr. E. Thornton, secretary of the United Textile Factory Workers Association and secretary of the Rochdale Weavers' Association, have been appointed members of the Advisory Council to the Committee of the Privy Council for Scientific and Industrial Research. Sir John Greenly retired from the Council on completion of his term of office on Septemter 30.

THe College of Physicians of Philadelphia has awarded the Alvarenza Prize to Dr. Ernest Carroll Faust, professor of medical parasitology and acting head of the Department of Tropical Medicine, Tulane University, for his "outstanding contributions to our knowledge of parasitology and tropical medicine".

THE centenary meeting of the Royal Anthropological Institute will be held on October 30. Prof. J. H. Hutton, president of the Institute, will preside, and addresses will be delivered by Sir John Myres on the work of the Institute, and by Lord Hailey on "The Role of Anthropology in Colonial Develop. ment" during the morning. The aftornoon meeting will take the form of a symposium on "The Future of Anthropology", in which Dr. G. M. Morant will speak on physical anthropology, Prof. V. G. Childe on archæulogy, Mr. R. U. Sayce on material culture and Prof. R. Firth on social anthropology. The morning meetings will be at the rooms of the Royal Society and the afternoon meetings at the Institute.

The Nutrition Society has arranged a whole-day conference on "Post-war Nutritional Relief", at the London School of Hygiene and Tropical Medicino, Keppel Street, W.C.I, on November 6. The chair will be taken by Lord, Horder and papers will be read by Prof. J. R. Marrack ("Past Experience and Present Position"), Dr. J. Hammond ("Problems of Production in Relation to Post-war Nutritional Relief"), Miss E. M. M. Hume ("Opportunities for Nutritional Research in the Work of Relief") and others. Details of this meeting can be obtained from the hon. secretary, Dr. Leslie J. Harris, Nutritional Laboratory, Milton Road, Cambridge. 